\title{
Rural households' preferences and attitudes towards biomass fuels - results from a comprehensive field survey in Bangladesh
}

\author{
Md Kamrul Hassan*, Pradipta Halder, Paavo Pelkonen and Ari Pappinen
}

\begin{abstract}
Background: Biomass fuel is the main source of rural household energy in many developing countries in South and Southeast Asia. This paper examines the preference and attitude towards biomass fuels of consumers living in rural areas of Bangladesh.

Methods: A questionnaire survey was conducted to collect data of 240 households from four upazilas located in four distinct agro-ecological zones of Bangladesh. Different inferential statistical tests were carried out to analyze the information.

Results: The results revealed that branches, leaves, cow dung, rice straw and stem wood were the most commonly used biomass fuels, whereas the most preferred biomass fuels were firewood (branches and stem wood) followed by cow dung, bamboo and jute stalk. Due to the short supply of firewood, the rural households opted for inferior types of biomass such as leaves, twigs, rice straw and other crop residues. Samanea saman, Albizia procera and Mangifera indica are the main preferred firewood tree species. The analysis showed that the consumption patterns of and preferences for biomass fuels significantly varied between the regions and the socio-economic groups. The economic inability of consumers to afford commercial fuels was the main reason for the widespread use of biomass fuels. Nevertheless, the majority of the rural households posed positive attitudes towards an on-farm and off-farm afforestation programme as a response to a future supply of biomass fuel.

Conclusions: The study demonstrated that firewood was the most preferred biomass fuel and, as a consequence, the current consumption was not sustainable. Therefore, extensive farming of various fast growing firewood species both in private and public lands has been solicited to bridge the gap between demand and supply.
\end{abstract}

Keywords: Preference; Attitude; Biomass fuel; Rural household; Bangladesh

\section{Background}

Biomass fuels form the most significant indigenous sources of rural household energy in many countries of South and Southeast Asia such as Bangladesh, Bhutan, Cambodia, India, Laos, Myanmar, Pakistan, Sri Lanka and Vietnam [1]. Almost all the countries in these regions are major bioenergy consumers as well as producers [2]. Biomass fuel is mainly used for cooking, rice parboiling and occasionally space heating. In Bangladesh, almost all rural households use biomass as their primary source of energy where over $90 \%$ of energy is supplied

\footnotetext{
* Correspondence: kamrul.hassan@uef.fi

School of Forest Sciences, University of Eastern Finland, P.O. Box 111, Joensuu FI-80101, Finland
}

from biomass fuels [3]. Biomass fuels are mainly supplied from trees of homestead and/or other secondary plantation forests. The way of collecting biomass fuels is unsustainable [3]. The main concerns are related to overexploitation of tree resources and conversion of woodlands to other non-forestry purposes, which potentially have negative impacts not only on climate change but also on local food and fuel production $[1,4,5]$. Moreover, the rural population is steadily increasing, alternative sources of energy have not been developed and there is an increased pressure on the existing tree resources [1,3]. Despite these concerns, little is known about the preferences of rural households in terms of biomass fuels and the way of harvesting and growing the

\section{实}


feedstock. Therefore, a detailed survey of the preferences and attitudes of consumers with regard to biomass fuel resources could be able to assist in developing biomassbased rural energy strategies as a solution of sustainable energy services.

Bangladesh has very sparse forest resources. The forest area of the country is about 2.52 million ha. The estimated annual deforestation rate of the country is $0.2 \%$ [6]. It has been reported that the forest resource of the country is used unsustainably [6]. Realizing the demand of firewood together with other wood products, the government of Bangladesh has been implementing a 20-year Forest Master Plan (FMP) since year 1993 [7]. Under the conditions of this FMP, a number of afforestation programmes have been launched. However, the production of firewood on the basis of such an afforestation programme has not been well documented [8]. The FMP estimated that the annual demand of firewood would reach at least 11.5 million $\mathrm{m}^{3}$ and the gap between demand and supply of firewood would grow to about 3.3 million $\mathrm{m}^{3}$ annually by 2013 [7]. In addition, there are many environmental uncertainties, which can further aggravate the firewood production situation and eventually lead to an acute scarcity of firewood supply in the country [1]. Moreover, it has been reported that the future supply of firewood will heavily rely on an afforestation programme for both private and public lands [1]. Therefore, sustainable forest and energy policies are necessary to incorporate both the supply side management through resource development and the demand side management through energy efficiency gains. Thus, the formulation of bioenergy-based rural energy strategies at either a regional or a national level requires a detailed and accurate assessment of the range of biomass fuel choice, existing biomass fuel resources and the involvement and attitudes of people in terms of bioenergy resource development. Furthermore, on the one hand, biomass fuel preference is directly related to the local available biomass and the socio-economic conditions of the consumers [9], and on the other hand, the investigations of public attitudes concerning various aspects of environmental issues are of high importance for resource development [10]. From these perspectives, it is relevant to explore and analyze the preferences and attitudes of rural households with regard to the existing biomass fuel resources, market strategies and their acceptability.

In Bangladesh, a number of studies have been conducted on various aspects of biomass fuels, but most of the earlier studies focused on either a specific area or a village level, or dealt to a lesser extent with supply and consumption patterns of biomass fuels [3]. So far, only a few studies on the biomass fuel preferences of rural households have been carried out. Miah et al. [11] investigated the preferred fuelwood species in four villages of Hathazari upazila in the Chittagong region. Jashimuddin et al. [12] studied the preference for and consumption of biomass fuels in some disregarded villages of two upazilas (sub-district) in the Noakhali region. Most of the early studies overlooked the preferences of consumers with regard to biomass fuels and their reactions to the future firewood supply. Moreover, the biomass fuel preferences among rural households and their involvement and attitudes in terms of afforestation programmes are poorly understood in the context of Bangladesh.

Therefore, the present study is carried out to draw a consistent picture on the commonly used and preferred biomass fuels, the dynamics of biomass fuel collection and the response of rural households to tree planting as a precaution of a future biomass fuel supply. The main objectives of this study were as follows:

1. To investigate the commonly used and preferred biomass fuels in rural households

2. To identify the preferred firewood tree species

3. To determine the dynamics of biomass fuel collection

4. To find out the underlying factors for using biomass fuel

5. To understand the attitudes of rural households in terms of tree planting and the afforestation programme as a response in order to meet the future biomass fuel demand

The information from this study may be relevant to the scientific community and to policy makers, bioenergy entrepreneurs and other stakeholders for formulating appropriate strategies for the future planning and development of bioenergy resources in Bangladesh and many other developing countries.

\section{Methods}

\section{Study area}

A comprehensive field survey was undertaken in four upazilas located in different agro-ecological zones (AEZ) of Bangladesh (Table 1). The four upazilas, which had been purposively selected for the study, were Kalaroa upazila of Satkhira district, Nachole upazila of ChapaiNabwabganj district, Nakla upazila of Sherpur district and Chakaria upazila of Cox's Bazar district. The Kalaroa upazila is situated in the southwestern part of the country, and the population density of this area reaches 1,028 persons $/ \mathrm{km}^{2}$. Major crops are rice, jute, sugarcane, potato and oilseed. The climate of this area is tropical and is characterized by a distinct rainy and a dry period. This area generally receives moderate rainfall and in 2010 the precipitation was $217 \mathrm{~cm} \mathrm{[13].} \mathrm{The}$ 
Table 1 Selected AEZ, upazila, union and village for the study

\begin{tabular}{|c|c|c|c|c|}
\hline AEZ classification ID & District & Upazila & Union & Village \\
\hline \multirow[t]{2}{*}{ AEZ ID 11} & Satkhira & Kalaroa & Jalalabad & Jalalabad, Shankarpur \\
\hline & & & Chandanpur & Chandanpur, Hizoldi \\
\hline \multirow[t]{2}{*}{ AEZ ID 25} & Chapai-Nababgang & Nachole & Kashba & Kendobona, Bailkapur \\
\hline & & & Nachole & Banipur, Darbeshpur \\
\hline \multirow[t]{2}{*}{ AEZ ID 9} & Sherpur & Nakla & Banesherdi & Banesherdi, Polardeshi \\
\hline & & & Ganapardi & Khrisnapur, Gajaria \\
\hline \multirow[t]{2}{*}{ AEZ ID 21} & Cox's Bazar & Chakaria & Illishia & Chuarphari, Darbeshkata \\
\hline & & & Badarkhali & Mongpara, Northpara \\
\hline
\end{tabular}

Nachole upazila is situated in the northwestern part of the country, and the population density reaches 517 persons $/ \mathrm{km}^{2}$. Major crops are rice, wheat, oilseed and pulse. The upazila is covered with Barind Tract (topography ranges from 15 to $50 \mathrm{~m}$ ) and characterized by undulating landscape. The climate of this upazila is mainly subtropical and characterized by a short rainy season and a long dry season. This area generally receives low fall and the precipitation in 2010 was $80 \mathrm{~cm}$ [13].

The Nakla upazila is located in the central-northern part of the country, about $40 \mathrm{~km}$ south of the foothills of the Meghalaya State of India. The population density of this area reaches 1,091 persons $/ \mathrm{km}^{2}$. The main crops of this area are rice, jute, wheat and potato. The climate of the upazila is tropical with sub-tropical climatic effects and is characterized by a short summer, a distinct long rainy season and winter. This area receives moderate rainfall and the annual rainfall in 2010 was $166 \mathrm{~cm}$ [13]. The Chakaria upazila, however, is situated in the southeastern coastal regions of Bangladesh and is characterized by river, tidal and estuarine floodplain landscape. The population density of this area reaches up to 942 persons $/ \mathrm{km}^{2}$. The climate of this area is also tropical and experiences a long rainy period and a short winter. This area generally receives high rainfall. The annual precipitation in 2010 was $344 \mathrm{~cm}$ [13].

\section{Survey procedure}

The study involved a socio-economic survey among rural households to explore their biomass fuel preferences and attitudes towards bioenergy in the selected four upazila (Table 1). The survey was conducted during autumn 2012. The survey was based on a three-stage stratified random sampling technique. The sampling technique employed in this study referred to previous studies $[3,11,12]$. The socio-economic information such as the number of households of the village and their income were obtained from the local 'union parishad' (local governmental administrative unit) office. Based on the monthly income of the households, the households of the selected village were broadly categorized into three socio-economic groups: rich (household monthly income more than BDT 12,000 or US\$150), middle class (household monthly income between BDT 6,000 and 12,000 or US\$75 and US\$150), and poor (household monthly income less than BDT 6,000 or US\$75). Similar types of methods for the categorization of the households were used in previous studies $[3,11]$. However, on the basis of the socio-economic status of a household, a total of 15 households (five households from each socioeconomic group) from each village were randomly selected. After selecting the households, the location of households was identified with the help of local volunteers. For this study, a total of 240 households from 16 villages under the jurisdictions of eight unions and four upazilas were selected (Table 1). The reconnaissance survey indicated that on average $8 \%$ of the households were found to be rich, $32 \%$ of them were middle class and $60 \%$ of them were poor. The average sampling intensity of households was $6.27 \%$, which was considered to be adequate for this study.

\section{Data collection}

The primary data were collected through household surveys. The adult male or female of the household was interviewed using a questionnaire consisting of both open- and closed-ended items. The interview was based on memory recall, knowledge and understanding of the use of biomass as a fuel, preferences and the development of resources of the respondent. The questionnaire consisted of two sections. In the first section, the questions were designed to explore the general information and to identify their preferred biomass fuels. The respondents were asked to provide an information of their educational level, occupation, types of biomass fuels used, preferred biomass fuels, preferred firewood species, collection of biomass fuels, types of difficulties during collection, whether they buy biomass fuels or not, and the reasons for the use of biomass fuels. The preferred firewood species were identified on the basis of firewood production, characteristics of firewood and availability. 
In the second section, the questions were related to the attitudes of the respondents to understand what actions they have taken for the future supply of biomass fuel. The respondents were asked about their involvement in tree plantations, their support for and expectations from the afforestation programme for government land, their recognition of any benefits from such programmes and their views regarding the importance of afforestation programmes. The questionnaire was originally written in English and then translated into Bengali. To ensure the validity of the questionnaire and the understanding of the questions, a pilot testing was administered to 30 households through the Divisional Forest Officers of Faridpur, Rajshahi and Moulavibazar. The pilot testing revealed that three items of the questionnaire had not been clearly understood by the majority of the respondents, and they were restructured in the final surveys for a better understanding. Based on the feedback from the respondents and suggestions from the Divisional Forest Officers and bioenergy experts of the University of Eastern Finland, three misunderstood items were excluded and another two were reformulated.

\section{Data analysis}

The quantitative analysis was conducted by using the SPSS 19.0 program. The descriptive statistics such as cross tabs and percentages were analyzed to find out the average rating of different statements of the respondents. In this analysis, different statements of the respondents were considered as variables whereas the regions and the socio-economic groups were considered as fixed factors or parameters. An inferential statistical method such as a one-way analysis of variance (One-way ANOVA) was applied to compare the average ratings of the variables. Furthermore, the post hoc 'Tukey' test was used to compare the mean differences between the parameters.

\section{Results}

Socio-economic characteristics of the respondents

Of the respondents, $75 \%$ were male. In terms of age, $40 \%$ of the respondents were between 25 and 39 years, $45 \%$ of them were between 40 and 54 years, and $15 \%$ of them were above 55 years old. Of the respondents, $41 \%$ were farmers, $25 \%$ labours, $6 \%$ businessman, $8 \%$ service holders and $20 \%$ unemployed. The literacy rate of the respondents was $63 \%$, of which $33 \%$ had primary education, $21 \%$ had secondary-level education and $9 \%$ had university-level education.

\section{Use of and preferences for biomass fuels}

All respondents reported that they were dependent on biomass fuels for cooking, rice parboiling and water heating. Biomass fuels in the study areas were firewood which consisted of stem wood and branches, leaves and twigs, bamboo, rice husk, rice straw, jute stalk, agricultural residues, cow dung, briquette and saw mill residues. Among the respondents, 60\% reported that they used stem wood as a fuel while $75 \%$ preferred this fuel (Table 2). The use of and giving preference to stem wood as a fuel were significantly different between the regions (One-way ANOVA $F_{1,3}=4.78 ; p<0.01$ and $F_{1,3}=9.91 ; p<0.01$, respectively). Table 3 represents the corresponding results of One-way ANOVA with the post hoc Tukey test. In Chakaria region, there is a large area of government forest lands, where the inhabitants of this region are able to find a better supply of stem firewood, but in other study areas, there are no such government forest lands. The use of stem wood as a fuel was also significantly different between the socio-economic groups (One-way ANOVA $F_{1,2}=36.36 ; p<0.01$ ). It was observed that the rich households were the main consumers of stem firewood. Nevertheless, all respondents used branches as a fuel and preferred this fuel. Although nearly all rural households used leaves and twigs as a

Table 2 Use of and preferences for biomass fuels among the respondents (\%) in different regions

\begin{tabular}{|c|c|c|c|c|c|c|c|c|c|c|}
\hline \multirow{2}{*}{$\begin{array}{l}\text { Types of biomass } \\
\text { fuels }\end{array}$} & \multicolumn{2}{|c|}{ Kalaroa $(N=60)$} & \multicolumn{2}{|c|}{ Nachole $(N=60)$} & \multicolumn{2}{|c|}{ Nakla $(N=60)$} & \multicolumn{2}{|c|}{ Chakaria $(N=60)$} & \multicolumn{2}{|c|}{ Average $(N=240)$} \\
\hline & Use & Preference & Use & Preference & Use & Preference & Use & Preference & Use & Preference \\
\hline Stem wood & 50 & 60 & 55 & 75 & 55 & 67 & 80 & 98 & 60 & 75 \\
\hline Branches & 100 & 100 & 100 & 100 & 100 & 100 & 100 & 100 & 100 & 100 \\
\hline Leaves and twigs & 97 & 30 & 100 & 37 & 93 & 33 & 95 & 32 & 96 & 33 \\
\hline Bamboo & 37 & 52 & 45 & 83 & 30 & 63 & 28 & 55 & 35 & 63 \\
\hline Rice husk & 48 & 18 & 20 & 10 & 38 & 30 & 0 & 0 & 27 & 15 \\
\hline Rice straw & 68 & 2 & 88 & 15 & 73 & 27 & 30 & 5 & 65 & 12 \\
\hline Jute stalk & 90 & 97 & 0 & 0 & 73 & 98 & 0 & 0 & 41 & 49 \\
\hline Other crop residues & 88 & 10 & 47 & 12 & 53 & 7 & 30 & 2 & 55 & 8 \\
\hline Cow dung & 90 & 60 & 100 & 100 & 22 & 10 & 95 & 97 & 77 & 67 \\
\hline Briquette & 2 & 30 & 0 & 12 & 0 & 20 & 2 & 25 & 3 & 22 \\
\hline Saw mill residues & 12 & 40 & 3 & 28 & 7 & 38 & 12 & 55 & 8 & 40 \\
\hline
\end{tabular}


Table 3 Results of post hoc Tukey test: variables related to the use of and preference for biomass fuels $(N=240)$ Variables

Parameters

\begin{tabular}{|c|c|c|c|c|c|c|}
\hline \multirow{3}{*}{ Use of stem wood } & \multicolumn{3}{|c|}{ Regions } & \multicolumn{3}{|c|}{ Socio-economic groups } \\
\hline & \multirow{2}{*}{ Mean \pm sd. } & \multirow{2}{*}{$\begin{array}{c}\text { Mean } \pm \text { sd. } \\
\mathrm{K}(0.50 \pm 0.50)\end{array}$} & \multirow{2}{*}{$\begin{array}{l}p \text { value } \\
p<0.01\end{array}$} & \multirow{2}{*}{$\begin{array}{c}\text { Mean } \pm \text { sd. } \\
R(0.86 \pm 0.35)\end{array}$} & \multirow{2}{*}{$\begin{array}{c}\text { Mean } \pm \text { sd. } \\
M(0.65 \pm 0.48)\end{array}$} & \multirow{2}{*}{$\begin{array}{l}\boldsymbol{p} \text { value } \\
p<0.01\end{array}$} \\
\hline & & & & & & \\
\hline & $C(0.80 \pm 0.40)$ & $\mathrm{Na}(0.55 \pm 0.50)$ & $p<0.05$ & $R(0.86 \pm 0.35)$ & $P(0.29 \pm 0.46)$ & $p<0.01$ \\
\hline & $C(0.80 \pm 0.40)$ & $N(0.55 \pm 0.50)$ & $p<0.05$ & $M(0.65 \pm 0.48)$ & $P(0.29 \pm 0.46)$ & $p<0.01$ \\
\hline \multirow[t]{3}{*}{ Preference for stem wood } & $C(0.98 \pm 0.13)$ & $K(0.69 \pm 0.49)$ & $p<0.01$ & & & \\
\hline & $C(0.98 \pm 0.13)$ & $\mathrm{Na}(0.75 \pm 0.44)$ & $p<0.01$ & & & \\
\hline & $C(0.98 \pm 0.13)$ & $N(0.67 \pm 0.48)$ & $p<0.01$ & & & \\
\hline \multirow[t]{2}{*}{ Use of bamboo } & & & & $R(0.45 \pm 0.50)$ & $P(0.16 \pm 0.37)$ & $p<0.01$ \\
\hline & & & & $R(0.44 \pm 0.50)$ & $R(0.16 \pm 0.37)$ & $p<0.01$ \\
\hline \multirow[t]{2}{*}{ Preference for bamboo } & $\mathrm{Na}(0.83 \pm 0.38)$ & $K(0.52 \pm 0.50)$ & $p<0.01$ & & & \\
\hline & $\mathrm{Na}(0.83 \pm 0.38)$ & $C(0.55 \pm 0.50)$ & $p<0.01$ & & & \\
\hline \multirow[t]{4}{*}{ Use of rice husk } & $K(0.48 \pm 0.50)$ & $\mathrm{Na}(0.20 \pm 0.40)$ & $p<0.01$ & $R(0.16 \pm 0.37)$ & $P(0.35 \pm 0.48)$ & $p<0.05$ \\
\hline & $K(0.48 \pm 0.50)$ & $C(0.00 \pm 0.00)$ & $p<0.01$ & & & \\
\hline & $N(0.38 \pm 0.49)$ & $C(0.00 \pm 0.00)$ & $p<0.01$ & & & \\
\hline & $\mathrm{Na}(0.20 \pm 0.40)$ & $C(0.00 \pm 0.00)$ & $p<0.05$ & & & \\
\hline \multirow[t]{3}{*}{ Preference for rice husk } & $K(0.18 \pm 0.39)$ & $C(0.00 \pm 0.00)$ & $p<0.05$ & & & \\
\hline & $N(0.30 \pm 0.46)$ & $C(0.00 \pm 0.00)$ & $p<0.01$ & & & \\
\hline & $N(0.30 \pm 0.46)$ & $\mathrm{Na}(0.10 \pm 0.46)$ & $p<0.01$ & & & \\
\hline \multirow[t]{3}{*}{ Use of rice straw } & $C(0.30 \pm 0.46)$ & $K(0.68 \pm 0.47)$ & $p<0.01$ & $R(0.53 \pm 0.50)$ & $P(0.78 \pm 0.42)$ & $p<0.01$ \\
\hline & $C(0.30 \pm 0.46)$ & $\mathrm{Na}(0.88 \pm 0.32)$ & $p<0.01$ & & & \\
\hline & $C(0.30 \pm 0.46)$ & $N(0.73 \pm 0.45)$ & $p<0.01$ & & & \\
\hline \multirow[t]{2}{*}{ Preference for rice straw } & $N(0.27 \pm 0.45)$ & $K(0.02 \pm 0.36)$ & $p<0.01$ & & & \\
\hline & $N(0.27 \pm 0.45)$ & $C(0.02 \pm 0.13)$ & $p<0.01$ & & & \\
\hline \multirow[t]{5}{*}{ Use of jute stalk } & $K(0.90 \pm 0.30)$ & $\mathrm{Na}(0.00 \pm 0.00)$ & $p<0.01$ & & & \\
\hline & $K(0.90 \pm 0.30)$ & $C(0.00 \pm 0.00)$ & $p<0.01$ & & & \\
\hline & $K(0.90 \pm 0.30)$ & $N(0.73 \pm 0.47)$ & $p<0.01$ & & & \\
\hline & $N(0.73 \pm 0.47)$ & $\mathrm{Na}(0.00 \pm 0.00)$ & $p<0.01$ & & & \\
\hline & $N(0.73 \pm 0.47)$ & $C(0.00 \pm 0.00)$ & $p<0.01$ & & & \\
\hline \multirow[t]{4}{*}{ Preference for jute stalk } & $K(0.97 \pm 0.18)$ & $\mathrm{Na}(0.00 \pm 0.00)$ & $p<0.01$ & & & \\
\hline & $K(0.97 \pm 0.18)$ & $C(0.00 \pm 0.00)$ & $p<0.01$ & & & \\
\hline & $N(0.98 \pm 0.13)$ & $\mathrm{Na}(0.00 \pm 0.00)$ & $p<0.01$ & & & \\
\hline & $N(0.98 \pm 0.13)$ & $C(0.00 \pm 0.00)$ & $p<0.01$ & & & \\
\hline \multirow[t]{4}{*}{ Use of other crop residues } & $K(0.88 \pm 0.32)$ & $\mathrm{Na}(0.47 \pm 0.50)$ & $p<0.01$ & $R(0.43 \pm 0.50)$ & $P(0.70 \pm 0.46)$ & $p<0.01$ \\
\hline & $K(0.88 \pm 0.32)$ & $N(0.53 \pm 0.50)$ & $p<0.01$ & $\mathrm{M}(0.51 \pm 0.50)$ & $P(0.70 \pm 0.46)$ & $p<0.05$ \\
\hline & $K(0.88 \pm 0.32)$ & $C(0.30 \pm 0.46)$ & $p<0.01$ & & & \\
\hline & $\mathrm{N}(0.53 \pm 0.50)$ & $C(0.30 \pm 0.46)$ & $p<0.05$ & & & \\
\hline \multirow[t]{3}{*}{ Use of cow dung } & $N(0.22 \pm 0.42)$ & $K(0.90 \pm 0.30)$ & $p<0.01$ & & & \\
\hline & $N(0.22 \pm 0.42)$ & $\mathrm{Na}(1.00 \pm 0.00)$ & $p<0.01$ & & & \\
\hline & $N(0.22 \pm 0.42)$ & $C(0.95 \pm 0.22)$ & $p<0.01$ & & & \\
\hline \multirow[t]{3}{*}{ Preference for cow dung } & $K(0.60 \pm 0.49)$ & $\mathrm{Na}(1.00 \pm 0.00)$ & $p<0.01$ & & & \\
\hline & $K(0.60 \pm 0.49)$ & $N(0.10 \pm 0.30)$ & $p<0.01$ & & & \\
\hline & $K(0.60 \pm 0.49)$ & $C(0.97 \pm 0.18)$ & $p<0.01$ & & & \\
\hline
\end{tabular}


Table 3 Results of post hoc Tukey test: variables related to the use of and preference for biomass fuels $(N=240)$ (Continued)

\begin{tabular}{|c|c|c|c|c|c|c|}
\hline & $\mathrm{Na}(1.00 \pm 0.00)$ & $N(0.10 \pm 0.30)$ & $p<0.01$ & & & \\
\hline & $N(0.10 \pm 0.30)$ & $C(0.97 \pm 0.18)$ & $p<0.01$ & & & \\
\hline Use of saw mill residue & & & & $R(0.14 \pm 0.35)$ & $P(0.01 \pm 0.11)$ & $p<0.01$ \\
\hline Preference for saw mill residue & $\mathrm{Na}(0.28 \pm 0.45)$ & $C(0.55 \pm 0.50)$ & $p<0.05$ & & & \\
\hline
\end{tabular}

K, Kalaroa; Na, Nachole; N, Nakla; C, Chakaria; R, rich; M, middle; P, poor.

fuel, only one third of them preferred this fuel. It implied that due to a lack of available firewood, the households had to use leaves and twigs which are inferior types of biomass fuel.

About $35 \%$ of the respondents reported that they used bamboo as a fuel and $63 \%$ of them gave preference to this fuel. A higher number of respondents in Nachole region reported using and giving preference to bamboo as a fuel. It was observed that the use of bamboo was mainly restricted within the rich and middle-class households who had bamboo clumps. The use of bamboo as a fuel varied between the socio-economic groups (Oneway ANOVA $\left.F_{1,2}=9.94 ; p<0.01\right)$. However, giving preference to bamboo as a fuel was also significantly different between the regions (One-way ANOVA $F_{1,3}=$ 5.49; $p<0.01$ ).

Approximately $27 \%$ of the respondents reported that they used rice husk as a fuel but only $15 \%$ of them gave preference to this fuel. Households from Chakaria region neither used nor preferred rice husk as a fuel. There were significant differences in the use of and giving preference to rice husk as a fuel between the regions (Oneway ANOVA $F_{1,3}=16.57 ; p<0.01$ and $F_{1,3}=8.49 ; p<$ 0.01 , respectively). The use of rice husk as a fuel was more frequent in poor households. There were significant differences in the use of rice husk as a fuel between the socio-economic groups (One-way ANOVA $F_{1,2}=$ $3.80 ; p<0.05)$. However, $65 \%$ of the respondents reported using rice straw mainly for rice parboiling, whereas only $11 \%$ of them preferred rice straw as a fuel. The use of and giving preference to rice straw as a fuel significantly varied between the regions (One-way ANOVA $F_{1,3}=20.07 ; p<0.01$ and $F_{1,3}=9.63 ; p<0.01$, respectively). The use of rice straw as a fuel was more frequent in poor households. There were significant differences in the use of rice straw as a fuel between the socio-economic groups (One-way ANOVA $F_{1,2}=5.69$; $p<0.01)$.

Jute stalk was observed to have been used as a fuel by the majority of rural households in Kalaroa and Nakla regions (Table 2). However, in Nachole and Chakaria regions, no respondent reported using jute stalk as a fuel; thus, they did not give preference to this fuel. The reason was non-cultivation of jute in these regions due to a lack of crop suitability. There were significant differences in the use of and giving preference to jute stalk as a fuel between the regions (One-way ANOVA $F_{1,3}=187.56$; $p<0.01$ and $F_{1,3}=1,538.61 ; p<0.01$, respectively). However, about $55 \%$ of the respondents used other crop residues mainly consisting of sugarcane bagasse and straw from wheat, mustard, sesame and lentil while only $8 \%$ of them gave preference to these residues as a fuel. The use of crop residues as a fuel significantly varied between the regions and between the socio-economic groups (One-way ANOVA $F_{1,3}=17.54 ; p<0.01$ and $F_{1,2}=6.64$; $p<0.01$, respectively). It was observed that the poor households frequently used other crop residues as a fuel. About $67 \%$ of the respondents reported that they used cow dung as a fuel while $77 \%$ of them gave preference to this fuel. In Nakla region, a less number of respondents reported using cow dung as a fuel. The use of and preference for cow dung as a fuel significantly varied between the regions (One-way ANOVA $F_{1,3}=104.56$; $p<0.01$ and $F_{1,3}=114.38 ; p<0.01$, respectively).

Some rural households reported the use of improved biofuels such as rice husk briquettes. About 3\% of the respondents used briquettes as a fuel while $22 \%$ of them gave preference to this fuel. It was observed that most of the rice husk briquette factories were located in urban and semi-urban areas due to power supply facility, transportation convenience and marketing facility. Rice husk briquettes were mostly available in urban and semiurban markets but were also found to be sold in some rural grocery shops. Nevertheless, saw mill residues mainly consisted of sawdust and slabs that were only occasionally used by rural households. About $8 \%$ of the respondents reported of the use while $40 \%$ of them gave preference to this fuel. The use of sawmill residues as a fuel significantly varied between the socio-economic groups (One-way ANOVA $F_{1,2}=4.41 ; p<0.01$ ). Furthermore, there were significant differences in giving preference to saw mill residues as a fuel between the regions (One-way ANOVA $F_{1,3}=3.08 ; p<0.05$ ).

\section{The preferred tree species for firewood production}

The rural households used either whole tree or lopped branches as firewood. Based on overall preferences, a list of preferred firewood species is presented in Table 4.

In Kalaroa region, Cocos nucifera and Mangifera indica were the most common tree species, whereas in 
Table 4 Preferred tree species for firewood production in different regions $(N=240)$

\begin{tabular}{|c|c|c|c|c|c|c|}
\hline \multirow[t]{2}{*}{ Local names } & \multirow[t]{2}{*}{ Scientific names } & \multirow{2}{*}{$\begin{array}{c}\text { Average } \\
\text { respondents } \\
\text { (\%) }\end{array}$} & \multicolumn{4}{|c|}{ Average respondents (\%) } \\
\hline & & & Kalaroa & Nachole & Nakla & Chakaria \\
\hline Rain tree ${ }^{a, b, c}$ & Samanea saman & 95 & 97 & 85 & 98 & 98 \\
\hline Shil Korai ${ }^{a, b}, c$ & Albizia procera & 89 & 67 & 97 & 100 & 92 \\
\hline $\mathrm{Am}^{\mathrm{a}}$ & Mangifera indica & 81 & 100 & 95 & 100 & 29 \\
\hline $\operatorname{Sisso}^{a, b}$ & Dalbergia sissoo & 80 & 42 & 85 & 93 & 98 \\
\hline||$_{\text {pil-ipil| }}^{\mid a, b, ~ c ~}$ & Leucaena leucocephala & 79 & 60 & 90 & 87 & 78 \\
\hline Akashmoni ${ }^{\mathrm{a}, \mathrm{b}}$, c & Acacia auriculiformis & 75 & 82 & 93 & 73 & 53 \\
\hline Babla ${ }^{a, b}$ & Acacia nilotica & 73 & 87 & 100 & 43 & 62 \\
\hline Mahagoni $i^{a, b}$ & Swietenia mahagoni & 72 & 88 & 63 & 90 & 48 \\
\hline Coconut $^{a}$ & Cocos nucifera & 72 & 100 & 3 & 88 & 95 \\
\hline Eucalyptus a, b, c & Eucalyptus camaldulensis & 70 & 32 & 68 & 83 & 98 \\
\hline Bansh $^{a, c}$ & Bambusa spp. & 67 & 72 & 82 & 77 & 37 \\
\hline Kanthal ${ }^{\mathrm{a}}$ & Artocarpus heterophyllus & 63 & 95 & 52 & 100 & 4 \\
\hline$J_{a m}{ }^{a, b}$ & Syzygium spp. & 55 & 63 & 65 & 82 & 10 \\
\hline Neem ${ }^{a, b}$ & Azadirachta indica & 54 & 65 & 95 & 48 & 7 \\
\hline Arjun $^{b, c}$ & Terminalia arjuna & 50 & 32 & 67 & 62 & 37 \\
\hline Gora-nim ${ }^{b}$ & Melia azedarach & 39 & 45 & 72 & 38 & 0 \\
\hline Gamar $^{a, b}$, c & Gmelina arborea & 37 & 7 & 5 & 78 & 57 \\
\hline Simul $^{\mathrm{a}, \mathrm{c}}$ & Bombax ceiba & 36 & 35 & 40 & 57 & 12 \\
\hline Boroi $^{a}$ & Ziziphus mauritiana & 34 & 45 & 47 & 40 & 5 \\
\hline Kadam $^{\mathrm{a}, \mathrm{b}}$ & Anthocephalus chinensis & 33 & 23 & 17 & 87 & 7 \\
\hline Segun ${ }^{a, c}$ & Tectona grandis & 31 & 8 & 2 & 73 & 40 \\
\hline Pitraj $^{a, b}$, c & Aphanamixis polystachya & 30 & 40 & 7 & 72 & 0 \\
\hline Khajur ${ }^{a, b}$ & Phoenix sylvestris & 29 & 75 & 40 & 0 & 0 \\
\hline
\end{tabular}

${ }^{a}$ Species that are grown and/or planted on homestead land; ${ }^{b}$ species that are planted on marginal lands for secondary plantation or social forestry; ${ }^{\mathrm{c}}$ species that are grown and/or planted in state forests.

Nachole region, they were Acacia nilotica and Albizia procera. In Nakla region, the most common tree species were A. procera, M. indica and Artocarpus heterophyllus, whereas in Chakaria region, they were Samanea saman, Dalbergia sissoo and Eucalyptus camaldulensis. However, the study showed that $S$. saman was the most preferred firewood species in all regions followed by $A$. procera, M. indica, Acacia auriculiformis, Leucaena leucocephala, D. sissoo and A. nilotica. Trees on homestead land, marginal lands, secondary plantation and state forests were the main sources for collecting firewood. There were 25 most preferred firewood species identified, of which 21 species are grown on homestead land, 16 species on marginal lands and/or secondary plantation forests and 12 species on state forests. Typically, marginal lands which consisted of roadside lands, railways and embankments as well as khas lands (government unleased lands) were observed to be exploited for strip plantation. In addition, some rich farmers raised small-scale $(<0.5$ ha) block plantation mainly with
Swietenia mahagoni, Tectona grandis and S. saman for both timber and firewood production.

\section{Collection of biomass fuels}

Biomass fuels were mainly collected by women and sometimes by all family members. About $60 \%$ of the respondents stated that biomass fuel collection was performed solely by women while $30 \%$ of them expressed that the task was performed by family members where women, men, adult boys and adult girls participated. Only $4 \%$ of the respondents reported that biomass fuel was collected by men. This study implied distinct ramification of the gender characteristic in biomass fuel collection. However, $6 \%$ of the respondents informed that they employed labours to collect biomass fuels for them.

In rich households, biomass fuel collection was performed by both family members $(43 \%)$ and women (38\%) where the family members played the leading role. In the middle-class households, it was mainly done by women (58\%) followed by family members (35\%). 
However, in the poor households, it was mostly performed by women (86\%) and occasionally by family members (14\%). The way of biomass fuel collection significantly varied between the socio-economic groups (One-way ANOVA $F_{1,2}=6.60 ; p \leq 0.01$ ). Thus, the result revealed that the socio-economic status influenced the role of gender in biomass fuel collection. Table 5 represents the corresponding results of One-way ANOVA with the post hoc Tukey test.

The rural households faced various challenges during biomass fuel collection. The study identified five broad categories of challenges. Biomass fuel transportation was the major challenge followed by physical labour, processing and procurement, climatic barrier and social barrier. Of the respondents, $25 \%$ stated that transportation was the major problem since biomass fuels had to be collected far away from their home; $24 \%$ of the respondents expressed that biomass fuel collection involved hard physical labour while $23 \%$ of them stated that they faced severe difficulties for processing and procurement of biomass fuel such as splitting, chipping, drying and storing. However, $20 \%$ of the respondents expressed that climatic barriers such as heavy rain, hot sunny days, and cold and windy days were the main challenges for biomass fuel collection. Moreover, $8 \%$ of the respondents felt that social reluctance was one of the main challenges for biomass fuel collection particularly from off-farm lands. Of the poor households, 24\% faced such problems. The study showed that the challenges of biomass collection were not the same for all socio-economic groups with significant variations found between the groups (One-way ANOVA $F_{1,2}=4.68 ; p \leq 0.05$ ).

About $30 \%$ of the respondents spent money for collecting biomass fuel. The expenditure included the costs for direct biomass fuel purchasing, transportation cost and labour cost. There were significant variations in spending money for biomass fuel collection between the regions (One-way ANOVA $F_{1,3}=9.12 ; p \leq 0.01$ ). For example, in Chakaria region, $55 \%$ of the households spent money for biomass collection, whereas in Kalaroa, Nachole and Nakla regions, about $27 \%, 18 \%$ and $20 \%$ of the households, respectively, spent money for biomass fuel collection. However, by socio-economic groups, $24 \%$ of the rich, $34 \%$ of the middle-class and $33 \%$ of the poor households spent money for biomass fuel collection.

\section{Reasons for using biomass fuels}

There were several reasons identified for the widespread use of biomass fuels. The reasons for using biomass fuel are presented Table 5. The economic inability of the people to afford other forms of fuel was the main reason for using biomass fuel. About $73 \%$ of the rich, $96 \%$ of the middle-class and all poor households were not able to afford other forms of fuels. This type of reason significantly varied between the socio-economic groups (Oneway ANOVA $\left.F_{1,2}=22.38 ; p<0.01\right)$. Table 6 represents the corresponding results of One-way ANOVA with the post hoc Tukey test.

Biomass fuel is cheaper than any other form of conventional fuel which was a reason for its widespread use. Although the availability of biomass fuels was also a major reason for the widespread use, the availability of biomass fuels was not the same in all regions. The availability of biomass fuels significantly varied between the regions (One-way ANOVA $F_{1,3}=12.75 ; p<0.01$ ). In regions like Nachole, the availability of biomass fuels was scarce due to less tree resources, and therefore, the households of this region were observed to balance their biofuel demand by using it economically or even reducing cooking times. Likewise, in Chakaria region, due to intensive aquaculture practice and salt cultivation, there were less biomass fuel resources; thus, the households of this region met their biomass fuel demand from the neighbouring public forests.

Furthermore, the accessibility of local biomass fuels to all socio-economic groups was not equal, and there were statistically significant differences between the socio-economic groups (One-way ANOVA $F_{1,2}=3.33$;

Table 5 Results of post hoc Tukey test: variables related to biomass fuel collection $(N=240)$

\begin{tabular}{|c|c|c|c|c|c|c|}
\hline \multirow[t]{3}{*}{ Variables } & \multicolumn{6}{|c|}{ Parameters } \\
\hline & \multicolumn{3}{|c|}{ Regions } & \multicolumn{3}{|c|}{ Socio-economic groups } \\
\hline & Mean \pm sd. & Mean \pm sd. & $p$ value & Mean \pm sd. & Mean \pm sd. & $p$ value \\
\hline \multirow[t]{2}{*}{ Biomass fuel collection } & & & & $R(2.23 \pm 1.15)$ & $P(2.73 \pm 0.69)$ & $p<0.01$ \\
\hline & & & & $M(2.28 \pm 0.98)$ & $P(2.73 \pm 0.69)$ & $p<0.01$ \\
\hline \multirow[t]{2}{*}{ Challenges of biomass fuel collection } & & & & $R(2.45 \pm 0.98)$ & $P(2.99 \pm 1.54)$ & $p<0.05$ \\
\hline & & & & $M(2.48 \pm 1.18)$ & $P(2.99 \pm 1.54)$ & $p<0.05$ \\
\hline \multirow[t]{3}{*}{ Pay for biomass fuel } & $C(0.55 \pm 0.50)$ & $K(0.27 \pm 0.45)$ & $p<0.01$ & & & \\
\hline & $C(0.55 \pm 0.50)$ & $\mathrm{Na}(0.18 \pm 0.39)$ & $p<0.01$ & & & \\
\hline & $C(0.55 \pm 0.50)$ & $N(0.20 \pm 0.40)$ & $p<0.01$ & & & \\
\hline
\end{tabular}

K, Kalaroa; Na, Nachole; N, Nakla; C, Chakaria; R, rich; M, middle; P, poor. 
Table 6 Results of post hoc Tukey test: variables related to reasons for biomass fuels $(N=240)$

\begin{tabular}{|c|c|c|c|c|c|c|}
\hline \multirow[t]{3}{*}{ Variables } & \multicolumn{6}{|c|}{ Parameters } \\
\hline & \multicolumn{3}{|c|}{ Regions } & \multicolumn{3}{|c|}{ Socio-economic groups } \\
\hline & Mean \pm sd. & Mean \pm sd. & $p$ value & Mean \pm sd. & Mean \pm sd. & $p$ value \\
\hline \multirow[t]{2}{*}{ Economic inability } & & & & $R(0.73 \pm 0.45)$ & $M(0.96 \pm 0.19)$ & $p<0.01$ \\
\hline & & & & $R(0.73 \pm 0.45)$ & $P(1.00 \pm 0.00)$ & $p<0.01$ \\
\hline \multirow[t]{4}{*}{ Availability of biomass } & $K(0.90 \pm 0.30)$ & $\mathrm{Na}(0.58 \pm 0.50)$ & $p<0.01$ & $R(0.84 \pm 0.37)$ & $P(0.68 \pm 0.47)$ & $p<0.05$ \\
\hline & $K(0.90 \pm 0.30)$ & $C(0.65 \pm 0.48)$ & $p<0.01$ & & & \\
\hline & $\mathrm{Na}(0.58 \pm 0.50)$ & $N(0.95 \pm 0.22)$ & $p<0.01$ & & & \\
\hline & $N(0.95 \pm 0.22)$ & $C(0.65 \pm 0.48)$ & $p<0.01$ & & & \\
\hline \multirow[t]{3}{*}{ Free of charge } & $C(0.40 \pm 0.49)$ & $K(0.78 \pm 0.42)$ & $p<0.01$ & & & \\
\hline & & $\mathrm{Na}(0.87 \pm 0.34)$ & $p<0.01$ & & & \\
\hline & & $N(0.77 \pm 0.43)$ & $p<0.01$ & & & \\
\hline
\end{tabular}

K, Kalaroa; Na, Nachole; N, Nakla; C, Chakaria; R, rich; M, middle; $P$, poor.

$p<0.05)$. However, in many places of the study areas, biomass fuels were collected freely, which perhaps was one of the reasons for the widespread use; $70 \%$ of the respondents supported this reason. This type of reason significantly varied between the regions (One-way ANOVA $\left.F_{1,3}=14.22 ; p<0.01\right)$. In Chakaria region, such reason was supported by only $40 \%$ of the respondents, whereas in Kalaroa, Nachole and Nakla, it was supported by $78 \%, 87 \%$ and $77 \%$ of the respondents, respectively (Table 7). Nearly half of the respondents informed that irregularity in the supply of conventional fuels was also a reason for using biomass fuel. In a situation where traditional biomass fuels become scarce, only the rich households might buy commercial fuels such as LPG, kerosene and coal. Less than half of the respondents expressed that handling convenience was a reason for using biomass. However, the last two reasons were not statistically significant.

\section{Attitudes towards tree planting as a response to meeting the demand for firewood}

On-farm tree planting was observed as an agricultural practice by many rural households in the study areas. About $70 \%$ of the respondents informed that they have planted trees on their farmlands during the last 6 years while only half of them informed that they have planted trees within the last 3 years (Table 8 ). The numbers of on-farm tree planters (in this study, a tree planter is the one who planted at least one tree each year during the last 3 years) were significantly varied between the regions (One-way ANOVA $F_{1,3}=3.62 ; p<0.05$ ). Table 9 represents the corresponding results of One-way ANOVA with the post hoc Tukey test. In Chakaria and Nachole regions, there were less numbers of tree planters compared to other regions. Furthermore, the numbers of on-farm tree planters also varied significantly between the socio-economic groups (One-way ANOVA $F_{1,2}=67.73 ; p<0.01$ ). About $50 \%$ of the rich, $40 \%$ of the middle-class and only $12 \%$ of the poor households were involved in tree planting during the last 3 years. Lack of available land, unavailability of seedling together with high seedling cost, and insufficient knowledge of tree planting were recognized as the major causes that halt the rural households in tree planting on their farms.

About $85 \%$ of the respondents supported off-farm tree planting on public marginal lands such as roadsides, railways, embankment and other khas lands. The results suggested that tree planting on off-farm lands is important as it may produce additional biofuels for the rural households in a similar environment. However, the attitudes of the respondents towards tree planting on offfarm land significantly varied between the regions (One-way ANOVA $F_{1,3}=4.27 ; p>0.01$ ) and between

Table 7 Reasons for the use of biomass fuels by rural households $(N=240)$

\begin{tabular}{|c|c|c|c|c|c|}
\hline Reasons for the use of biomass fuels & Kalaroa (\%) & Nachole (\%) & Nakla (\%) & Chakaria (\%) & Average (\%) \\
\hline Economic inability & 85 & 95 & 90 & 88 & 90 \\
\hline Cheaper than other fuels & 88 & 92 & 77 & 83 & 85 \\
\hline Availability of biomass fuels & 90 & 58 & 95 & 65 & 77 \\
\hline Free of cost of biomass fuels & 78 & 87 & 77 & 40 & 70 \\
\hline Irregularity in the supply of LPG and other commercial fuels & 53 & 50 & 57 & 52 & 53 \\
\hline Handling convenience & 43 & 53 & 47 & 40 & 46 \\
\hline
\end{tabular}


Table 8 Attitudes towards tree planting and the afforestation programme of rural households in different regions $(N=240)$

\begin{tabular}{|c|c|c|c|c|c|}
\hline Attitude towards plantation & Kalaroa (\%) & Nachole(\%) & Nakla (\%) & Chakaria (\%) & Average $(\%)$ \\
\hline Tree planted within 6 years & 83 & 63 & 76 & 59 & 70 \\
\hline Tree planted within 3 years & 47 & 23 & 35 & 32 & 34 \\
\hline Agree in AF on government land & 75 & 90 & 78 & 95 & 85 \\
\hline Expectation from government AF & 85 & 90 & 92 & 98 & 91 \\
\hline Benefit received from government $\mathrm{AF}$ & 12 & 30 & 18 & 43 & 26 \\
\hline View on necessity of AF & 93 & 95 & 77 & 90 & 86 \\
\hline
\end{tabular}

$\mathrm{AF}$, afforestation.

the socio-economic groups (One-way ANOVA $F_{1,2}=$ $4.35 ; p<0.05)$. A higher percentage of respondents in Chakaria and Nachole regions supported off-farm tree planting for the reason that they had little option for on-farm tree planting. About $8 \%$ of the rich, $4 \%$ of the middle-class and $3 \%$ of the poor households did not support off-farm tree planting. Most of the rich households argued that off-farm tree planting caused a barrier for crop cultivation, while the middle-class and poor households claimed that such tree planting might cause land block and generate social conflicts.

Over $90 \%$ of the respondents stated their expectations from the off-farm afforestation programme of government lands. The expectations were in terms of better timber and firewood supply (39\%), financial support (23\%), environmental services (21\%) and training and job (8\%). Of the respondents, $26 \%$ informed that they received benefits from the previous governmental afforestation programme; $13 \%$ of the households received benefit in terms of firewood supply, 11\% for training and jobs, and less than $1 \%$ (one respondent) for financial support. The types of benefits received by the respondents significantly varied between the regions (One-way ANOVA $\left.F_{1,3}=6.45 ; p<0.01\right)$ and between the socioeconomic groups (One-way ANOVA $F_{1,2}=3.74 ; p<$ 0.05). However, the study showed that only a few households or a segment of the local community received any benefit from governmental afforestation programmes. On the other hand, the majority of the rural households did not receive such benefits from those programmes. The reasons for this were lack of information (37\%), lack of willingness to be involved in the programme (25\%) and lack of communication (12\%). Nevertheless, $86 \%$ of the respondents expressed their concerns regarding the necessity of governmental afforestation programmes in their regions. This attitude varied significantly between the regions (One-way ANOVA $F_{1,3}=3.30 ; p<0.05$ ) and between the socio-economic groups (One-way ANOVA $\left.F_{1,2}=6.25 ; p<0.01\right)$. A higher number of respondents in Nachole and Chakaria regions supported the necessity of an afforestation programme in their regions. However, the results indicated that the expectations towards a future firewood supply from the governmental afforestation programme were crucial and need to be taken into account.

\section{Discussion}

The aims of the study were to assess the rural preferences of households to biomass fuels and their attitudes towards planting as a response to meeting the demand for future biomass fuel supply. A survey was conducted among rural households of four upazilas located in four different agro-ecological zones of Bangladesh. The study showed that firewood had widespread use and it was the

Table 9 Results of post hoc Tukey test: variables related to attitudes towards tree planting and afforestation programme $(N=240)$

\begin{tabular}{|c|c|c|c|c|c|c|}
\hline \multirow[t]{3}{*}{ Variables } & \multicolumn{6}{|c|}{ Parameters } \\
\hline & \multicolumn{3}{|c|}{ Regions } & \multicolumn{3}{|c|}{ Socio-economic groups } \\
\hline & Mean \pm sd. & Mean $\pm s d$ & $p$ value & Mean \pm sd. & Mean \pm sd. & $p$ value \\
\hline \multirow[t]{2}{*}{ On-farm tree planting } & $\mathrm{K}(0.83 \pm 0.37)$ & $C(0.60 \pm 0.49)$ & $p<0.05$ & $R(0.95 \pm 0.22)$ & $P(0.33 \pm 0.47)$ & $p<0.01$ \\
\hline & & & & $M(0.85 \pm 0.36)$ & $P(0.33 \pm 0.47)$ & $p<0.01$ \\
\hline \multirow[t]{2}{*}{ Off-farm tree planting } & $K(0.75 \pm 0.44)$ & $C(0.95 \pm 0.22)$ & $p<0.01$ & $R(0.75 \pm 0.44)$ & $M(0.89 \pm 0.32)$ & $p<0.05$ \\
\hline & $\mathrm{N}(0.78 \pm 0.42)$ & $C(0.95 \pm 0.22)$ & $p<0.05$ & $R(0.75 \pm 0.44)$ & $P(0.90 \pm 0.30)$ & $p<0.05$ \\
\hline \multirow[t]{2}{*}{ Benefit received } & $\mathrm{K}(0.12 \pm 0.32)$ & $C(0.43 \pm 0.50)$ & $p<0.01$ & $R(0.31 \pm 0.47)$ & $P(0.15 \pm 0.36)$ & $p<0.05$ \\
\hline & $N(0.18 \pm 0.39)$ & $C(0.43 \pm 0.50)$ & $p<0.01$ & $M(0.31 \pm 0.47)$ & $P(0.15 \pm 0.36)$ & $p<0.05$ \\
\hline Necessity of AF & $\mathrm{Na}(0.95 \pm 0.22)$ & $\mathrm{N}(0.77 \pm 0.43)$ & $p<0.05$ & $R(0.78 \pm 0.42)$ & $P(0.96 \pm 0.19)$ & $p<0.01$ \\
\hline
\end{tabular}

K, Kalaroa; Na, Nachole; N, Nakla; C, Chakaria; R, rich; M, middle; P, poor; AF, afforestation. 
most preferred biomass fuel to any other form of biomass fuels. A similar pattern of firewood use and preference by rural households also emerged in other studies $[3,12,14,15]$.

It was observed that the rural households met the large portion of their firewood demand from homestead trees and partly from trees planted on governmentowned marginal lands. In Chakaria region, firewood is supplied from government reserve forests, which is a cause of concern for deforestation and destruction of the health and vitality of the existing forests. On the other hand, the scarcity of firewood in Nachole region resulted from less tree resources. The gap between demand and supply of firewood could be bridged through extensive plantation with fast growing tree species. However, a variation in the use of and preference for firewood by rural households among the socio-economic groups was also reported in previous studies $[3,11]$. Differences in the use of and preferences for firewood among the socio-economic groups were also observed in rural India [16].

However, the results showed that there was a skewed distribution in ownership and control of firewood resources between the socio-economic groups. It was observed that the rich households preferred to replace inferior types of biomass fuels with firewood, the middle-class households preferred a mixture of both types and the poor households opted for inferior types of biomass fuels.

The study envisaged that insufficient supply of firewood was the major driving factor for using other forms of biomass fuels. Although bamboo has been used traditionally as a substitute of firewood, it became scarce for cooking fuel as a result of depletion of the resources and increasing use in construction works. The use of and preference for bamboo as a fuel were mainly concentrated in some rich and a few middle-class households who had bamboo culms on their homestead. However, various agricultural crop residues such as rice straw, rice husk, jute stalk, sugarcane bagasse, and straw from wheat, mustard, sesame and lentil are used by all socioeconomic groups. The rice straw is mainly used as cooking fuel by the poor households who do not have much option for other biomass fuels, whereas the middle-class and rich households use it for rice parboiling. Although jute stalk is a popular cooking fuel in Kalaroa and Nakla regions, in Nachole and Chakaria regions, this crop is not cultivated due to a lack of suitability. Likewise, many other crops such as wheat, sugarcane, mustard, sesame and lentil do not grow uniformly in all the regions. Therefore, the availability of residues for fuel varied with regions. The crop residues were however used together with firewood at varying proportions and not in isolation, except by a few rich households in the study area.
Cow dung has been used traditionally as a fuel in many parts of Bangladesh [3,15,17]. Generally, the households collect cow dung throughout the year and make flat cakes, place it for drying and subsequently collect it for either direct use or storage for crisis time. In Nakla region, a less number of households gave preference to cow dung as a fuel. Most of the households of this region preserved cow dung for unprocessed organic manure and subsequently either used it on their farm lands or sold it for cash. However, the use of rice husk briquettes and saw mill residues is largely dependent on the availability in the local market. Therefore, a less number of respondents gave preference to these fuels.

In rural Bangladesh, more than $90 \%$ of firewood demand is met from homestead forests [18]. In homestead, various fruit trees such as $M$. indica, A. heterophyllus, Syzygium spp. and Ziziphus mauritiana were common in all the regions. Various palm trees such as C. nucifera, Phoenix sylvestris and Borassus flabellifer grow in both homestead and on-farm lands. However, these palms were not common in all regions. The fronds from these palms are used for biofuels. About 6 to 14 fronds (depending on the palm species) are shed per year from a palm tree, yielding about 1.5 to $4 \mathrm{~kg}$ of dry biomass fuel per frond $[19,20]$. Apart from these fruit and palm trees, various timber species such as $S$. saman, A. procera, $A$. nilotica, S. mahagoni, E. camaldulensis and Azadirachta indica were observed to grow in homestead, which also yield a good amount of firewood. On the other hand, various fast growing tree species such as S. saman, $A$. procera, D. sissoo, A. auriculiformis, A. nilotica, Melia azedarach and Gmelina arborea were observed to have been planted on off-farm government marginal lands. Similar types of tree species distribution were also reported by other studies $[11,12,21]$.

Although there are a wide variety of biomass fuels available in countryside, not all of them are accessible for energy. Accessible biomass fuel depends on a number of factors such as illegal issues, ownership, objectives of management, distances and quality of materials [16]. However, women were the single predominant collector of biomass fuel in rural areas, though often this task was supported by their family members. Within households, where there were adult men and women, the gendered division of labour generally allocated women to collect biomass fuels. A similar type of gender disproportion in biomass fuel collection was observed in Kenya [22].

The poverty and energy nexus had assigned more roles and responsibilities to women than men [22]. In regions like Nachole, the poor women spent long hours collecting inferior types of biomass fuels such as straw, grass, leaves and twigs and carried them to their home on head load covering a long distance. The distance travelled to collect biomass fuel can also be taken as a proxy for 
scarcity and lack of tree resources. However, it is well documented that poor women in rural areas of developing countries generally spend more time and put hard labour to collect biomass fuels compared with men due to their traditional socio-cultural roles [23]. Nevertheless, Miah et al. [11] reported that men were the predominant collector of biomass fuel nearby secondary forests/plantations while women were the predominant collector from homestead. In many places of the study areas, there were no secondary plantations or secondary forests. Hence, the households met their cooking fuels mostly from homesteads and farms, where women spent long time for biomass fuel collection. As a result, women are likely to suffer for serious long-term physical damage from strenuous work without sufficient recuperation time.

The study recognized that economic inability was the main reason for using biomass fuels. The rural households of Bangladesh are dependent on the subsistence economy for their livelihood [17]. It has been reported that nearly $40 \%$ of the nation and $44 \%$ of the rural people of Bangladesh are below the poverty line [24]. Thus, the limitations of income inhabit rural households to access efficient and modern forms of fuels, especially for cooking. Moreover, cheap pricing and local availability of biomass fuels are also major driving factors for a widespread use of biomass fuels in the study area. It has been reported that biomass fuels constitute the cheapest and the most accessible source of cooking fuel for the majority of the rural people in the Asia and Pacific region [25]. Similar types of reasons for a widespread use of biomass fuels in rural areas were also observed in Nepal [26] and India [27].

Even though firewood was the most preferred biomass fuel among the rural households, the sustainable sources of firewood supply has been questioned by energy experts. An earlier study revealed that firewood constituted about $43 \%$ of all biomass fuels used in rural Bangladesh [3]. Homestead forests and secondary plantations were the main sources of supplying the firewood demand. The local villagers informed that the homestead forests had been subjected to overexploitation and posed a high risk to the existing resources. Due to a continuous decline in the availability of firewood from homestead and secondary plantation forests, the on-farm planting trees have become important. Planting trees on-farm can reduce the pressure on existing tree resources, reverse the trend of deforestation and provide firewood and timber for future use. However, only one third of the respondents were found to be a 'tree planter'. The study envisaged that the less number of tree planters could have a negative impact on the future firewood supply from onfarm lands. In addition, most of the tree planters planted fruit trees with the exception of some households who planted valuable timber tree species such as $S$. mahagoni and T. grandis. In fact, planting trees for firewood purposes by households was not common in the study area. There were only few evidences (less than $5 \%$ of the respondents) where planters planted trees themselves to meet their firewood demands. As a result, the future supply of firewood from rural homesteads may become faint. Moreover, unavailable land together with high seedling cost forced a considerable number of rural households to become a 'non-tree planter'. Such situations were even worse in poor households who were experiencing an acute lack of firewood supply.

The promotion of the afforestation programme regarding off-farm government-owned lands provides multiple benefits to rural households in Bangladesh. The majority of the rural households supported the afforestation programme regarding off-farm government-owned marginal lands. The main purpose of such afforestation programmes was identified to meet the firewood demand of the local communities. It implied the access to secure energy, especially for the supply of cooking fuel which was widely acknowledged as a critical foundation of sustainable rural development. Moreover, nearly $90 \%$ of the respondents perceived the importance of developing resources through an afforestation programme. This was due to the underlying belief in resource depletion together with the insecurity of the future energy supply, especially for cooking. Therefore, a future afforestation programme in rural areas is important and needs to be perceived by government agencies, local authorities, NGOs, farmers and their associations. In addition, factors hindering the afforestation programme, such as a lack of information and communication, lack of knowledge and technology, lack of incentives and lack of assuring the beneficiaries' rights, need to be addressed rationally. The successful implementation of the afforestation programme could provide a sustainable biofuel supply and provide rural households with much energy security. Afforestation programmes in rural areas, especially for firewood production, were also developed in many Asian countries such as India, China, Pakistan, Nepal, Myanmar, Indonesia and the Philippines [28].

However, the current National Forest Policy 1994 recognized the importance of the people's participation in forestry and encouraged their involvement in sustainable development, poverty alleviation, and forest protection and development [29]. The policy was formulated in the lineup of FMP. One of the objectives of this policy is to provide and implement an afforestation programme for both public and private lands. Moreover, the National Energy Policy 1996 committed to meet the energy needs of different zones of the country and socio-economic groups through institutional strategic frameworks [30]. The latter one, the Renewable Energy Policy 2008, 
emphasized to promote clean energy for Clean Development Mechanism (CDM) in Bangladesh [31]. In fact, there were no clear guidelines or directives on 'biomassbased energy strategies' in the country as practiced in many developed and developing countries, Australia [32] and India [33] for instance. Biomass-based energy strategies could help in resource development, enhancing the energy security at the local level, protecting public health and safety, providing opportunities for innovative biomass technologies and creating markets for improved biofuels [34]. In the context of rural Bangladesh, the formulation of 'biomass-based rural energy strategies' is therefore relevant for ensuring the energy security and improving the energy services to the rural households who largely depend on biomass for meeting their primary energy needs.

\section{Conclusions}

Firewood was found to be the most preferred biomass fuel among the rural households followed by cow dung and bamboo. Trees on homestead, marginal lands and/ or secondary plantation were the main sources of supplying firewood. Due to a short supply of firewood, most of the rural households opt for inferior types of biomass such as leaves and twigs, straw and crop husk. However, the current trends of firewood consumption were not sustainable. Hence, an extensive farming of various fast growing firewood species such as S. saman, A. procera, D. sissoo and A. auriculiformis in both private and public lands had been solicited to bridge the gap between the demand and supply of firewood. Nevertheless, the majority of the rural households had posed positive attitudes towards an afforestation programme. The information of this study will assist policy makers, together with related governmental and non-governmental implementing agencies, and other stakeholders to formulate biomass-based rural energy strategies at either a national or a regional level in Bangladesh as well as many other developing countries for ensuring local energy securities and promoting a sustainable energy supply.

\section{Competing interests}

The authors declare that they have no competing interests.

\section{Authors' contributions}

MKH was involved in designing the questionnaire, collecting the data in the field and preparing the manuscript. PH contributed to the design of the questionnaire and analysis of data. PP contributed in improving the text of the manuscript. AP provided his expertise on biomass fuel and social aspects of this study. All authors have read and approved the final manuscript.

\section{Authors' information}

MKH is a doctoral student at the School of Forest Sciences, University of Eastern Finland, Joensuu. He is engaged in conducting research on the development of rural bioenergy and municipal waste-based energy in Bangladesh. PH is a post-doc researcher at the School of Forest Sciences, University of Eastern Finland, Joensuu, and dealing research on knowledge, perceptions and attitudes towards bioenergy. PP is a Professor Emeritus at the School of Forest Sciences, University of Eastern Finland. Previously, he had held high-ranked academic positions such as Rector of the University and Dean of the Faculty of Forest Sciences of the University of Joensuu. Presently, he is involved in the implementation of a number of projects related to bioenergy in Finland and many other countries in Europe, Africa and Asia. AP is a Professor of the School of Forest Sciences, University of Eastern Finland, Joensuu. He is involved in conducting research on lignocellulosic biotechnology and restoration of indigenous forest in tropics.

\section{Acknowledgements}

The authors are thankful to Dr. Markku Huttunen, School of Forest Sciences, University of Eastern Finland, for his comments and improving the English language. In addition, the authors would also like to acknowledge all volunteers and respondents who provided their valuable time for this survey. Finally yet importantly, the financial support from the Graduate School of Forest Sciences at the University of Eastern Finland is acknowledged.

Received: 28 October 2013 Accepted: 25 November 2013 Published: 9 December 2013

\section{References}

1. Forest Resources Assessment (FRA) Programme (1999) Forest resources of Bangladesh, country report. Forest Resources Assessment 2000. Working Paper 15. FAO, Rome

2. Koopmans A (2005) Biomass energy demand and supply for South and South-East Asia-assessing the resource base. Biomass Bioenerg 28:133-150

3. Hassan MK, Pelkonen P, Halder P, Pappinen A (2012) An analysis of crosssectional variation in energy consumption pattern at the household level in disregarded rural Bangladesh. J Basic Appl Sci Res 2(4):3949-3963

4. Finco MVA, Doppler W (2010) Bioenergy and sustainable development: the dilemma of food security and climate change in the Brazilian savannah. Energy Sustain Dev 14(3):194-199

5. van Dam J, Junginger M, Faaij APC (2010) From the global efforts on certification of bioenergy towards an integrated approach based on sustainable land use planning. Renew Sustain Energy Rev 14(9):2445-2472

6. FAO (2011) State of the world's forests 2011. FAO, Rome, http://www.fao. org/docrep/013/i2000e/i2000e00.htm. Accessed 7 Mar 2013

7. Ministry of Environment and Forest (1992) Forestry master plan - forest production. ADB (TA No. 1355-BAN), UNDP/FAO BGD 88/025. Government of the People's Republic of Bangladesh, Dhaka

8. Mondal MAH, Denich M (2010) Assessment of renewable energy resources potential for electricity generation in Bangladesh. Renew Sustain Energy Rev 14:2401-2413

9. Kennes W, Parikh JK, Stolwijk H (1984) Energy from biomass by socioeconomic group - a case study of Bangladesh. Biomass 4:209-234

10. Lambrinou E, Sourtzi P, Kalokerinou A, Lemonidou C (2009) Attitudes and knowledge of the Greek nursing students towards older people. Nurs Educ Today 29(6):617-622

11. Miah MD, Ahmed R, Uddin MB (2003) Biomass fuels use by the rural households in Chittagong region, Bangladesh. Biomass Bioenerg 24(4/5):277-283

12. Jashimuddin M, Masum KM, Salam MA (2006) Preference and consumption pattern of biomass fuel in some disregarded villages of Bangladesh. Biomass Bioenerg 30(5):446-451

13. Bangladesh Bureau of Statistics (2011) Statistical yearbook of Bangladesh 2010. Statistics Division. Ministry of Planning, Government of the People's Republic of Bangladesh, Dhaka

14. Asaduzzaman M, Barnes DF, Khandker SR (2010) Restoring balance: Bangladesh's rural energy realities. World Bank Working Paper No. 181. Washington, DC, The World Bank

15. Miah MD, Kabir RRMS, Koike M, Akther S, Shin MY (2010) Rural household energy consumption pattern in the disregarded villages of Bangladesh. Energ Policy 38:997-1003

16. Mahapatra AK, Mitchell CP (1999) Biofuel consumption, deforestation, and farm level tree growing in rural India. Biomass Bioenerg 17:291-303

17. Asaduzzaman M, Latif A (2005) Energy for rural households: towards rural energy strategies in Bangladesh. Bangladesh Institute of Development Studies, Dhaka 
18. FAO (1998) Woodfuel in Bangladesh: production and marketing. RWEDP Report No. 38. Regional Wood Energy Development Programme in Asia, Bangkok

19. Koopmans A, Koppejan J (1997) Agricultural and forest residues generation, utilization and availability. Paper presented at the regional consultation on modern applications of biomass energy, Kuala Lumpur, Malaysia, http://ces.iisc.ernet.in/energy/HC270799/RWEDP/acrobat/ p_residues.pdf. Accessed 18 Jan 2013

20. Hassan MK, Pelkonen P, Pappinen A (2011) Assessment of bioenergy potential from major crop residues and wood fuels in Bangladesh. J Basic Appl Sci Res 1(9):1039-1051

21. Bangladesh Forest Department, Bangladesh Space Research and Remote Sensing Organization, FAO (2007) National forest and tree resources assessment 2005-2007. Bangladesh, Bangladesh Forest Department, Dhaka

22. Muchiri L (2008) Gender and equity in bioenergy access and delivery in Kenya. Practical Action Eastern Africa: Policy Innovation Systems for Clean Energy Security (PISCES). http://practicalaction.org/page/docs/consulting/ pisces/gender-and-equity-in-bioenergy-kenya.pdf. Accessed 3 Feb 2013

23. Lambrou Y, Piana G (2006) Energy and gender in rural sustainable development. FAO, Rome, http://www.fao.org/sd/dim_pe1/docs/ pe1_060501d1_en.pdf. Accessed 15 Feb 2013

24. World Bank (2008) Poverty assessment for Bangladesh: creating opportunities and bridging the east-west divide, Bangladesh Development Series. Paper No. 26. The World Bank Office, Dhaka

25. FAO (2009) Biomass energy in the Asia-Pacific region: current status, trends and future setting. Asia-Pacific Forestry Sector Outlook Study II. Working Paper No. APFSOS II/WP/2009/26. FAO, Bangkok

26. Soussan J, Gevers E, Ghimire K, O'Keefee P (1991) Planning for sustainability: access to firewood in Dhanusha district, Nepal. World Dev 20(10):1299-1314

27. Badola R (1998) Attitudes of local people towards conservation and alternatives to forest resources: a case study from the lower Himalayas. Biodivers Conserv 7:1245-1259

28. Mead DJ (2001) Plantation and wood energy. Forestry Department. Working Paper FD/5. Rome, Food and Agriculture Organization of the United Nations, ftp://ftp.fao.org/docrep/fao/006/ac125e/ac125e00.pdf. Accessed 15 Feb 2013

29. Ministry of Environment and Forest (1995) National forest policy Government of the People's Republic of. Bangladesh, Dhaka

30. Ministry of Power, Energy and Mineral Resources (2006) National energy policy. Government of the People's Republic of. Bangladesh, Dhaka

31. Ministry of Power, Energy and Mineral Resources (2008) Renewable energy policy of Bangladesh. Power Division, Government of the People's Republic of Bangladesh, Dhaka

32. Clean Energy Council (2008) Australian bioenergy roadmap: setting the direction for biomass in stationary energy to 2020 and beyond. http://www.econbiz.de/en/search/detailed-view/doc/all/australianbioenergy-roadmap-setting-the-direction-for-biomass-in-stationary-energyto-2020-and-beyond/10003800180/?no cache=1. Accessed 8 Mar 2013

33. Ministry of New \& Renewable Energy (2008) National policy on biofuels. Government of India, New Delhi, http://mnre.gov.in/file-manager/UserFiles/ biofuel_policy.pdf. Accessed 15 Mar 2013

34. O'Neill G (2012) 2012 Bioenergy action plan. California Energy Commission, Efficiency and Renewables Division. Publication No. CEC-300-2012-XXX-XXX., http://www.resources.ca.gov/docs/2012_Bioenergy_Action_Plan.pdf. Accessed 25 Feb 2013

doi:10.1186/2192-0567-3-24

Cite this article as: Hassan et al:: Rural households' preferences and attitudes towards biomass fuels - results from a comprehensive field survey in Bangladesh. Energy, Sustainability and Society 2013 3:24.

\section{Submit your manuscript to a SpringerOpen ${ }^{\circ}$ journal and benefit from:}

- Convenient online submission

- Rigorous peer review

- Immediate publication on acceptance

- Open access: articles freely available online

- High visibility within the field

- Retaining the copyright to your article

Submit your next manuscript at $>$ springeropen.com 